\title{
Минеральные виды Северной Карелии: типоморфные особенности фукситовых сланцев участка Хизоваара
}

Кулешевич Л.В.

ИГ КарНЦ РАН, Петрозаводск, kuleshev@krc.karelia.ru

Аннотация. Участок Хизоваара в С. Карелии известен своим нерудным сырьем - кианитом, мелкочешуйчатым мусковитом, гранатом, высокобарическими метасоматитами и коллекционными образцами (с фукситом, кианитом, гранатом). В изученных фукситовых сланцах установлены: 1 - примеси хрома в составе фуксита, кианита, ставролита, рутила, 2 - акцессорные алюмохромиты, Со-герсдорфит. Фукситовые сланцы образовались при метаморфизме ультраосновных пород, измененных в процессе более ранней гидротермально-метасоматической переработки под влиянием даек дацитов.

Ключевые слова: фукситовые сланцы, хромсодержащие силикаты, алюмохромиты, герсдорфит, Хизоваара, Северная Карелия.

\section{Mineral species of North Karelia: typomorphic characteristics of fuchsite schists from the Khizovaara prospect}

Kuleshevich L.V.

IG KarRCRAS, Petrozavodsk, kuleshev@krc.karelia.ru

Abstract. The Khizovaara prospect in North Karelia is known for its non-metalliferous raw materials, such as kyanite, fine-scaly muscovite, garnet, high-pressure metasomatic rocks, and samples for collections (with fuchsite, kyanite, and garnet). The analyzed fuchsite schists contain: 1 - chromium impurities as part of fuchsite, kyanite, staurolite and rutile, 2 - accessory alumochromites and Co-gersdorffite. Fuchsite schists were produced upon metamorphism of ultramafic rocks altered in earlier hydrothermal-metasomatic changes affected by dacite dykes.

Keywords: fuchsite schists, chrome-bearing silicates, alumochromites, gersdorffite, Khizovaara, North Karelia.

\section{Введение}

В С. Карелии наиболее хорошо изучены минеральные ассоциации метаморфических комплексов. При выполнении темы по минеральному разнообразию Карелии для территории С. Карелии (вошедшей в арктическую зону) проведено минералогическое районирование (по методике Юшкина, 1989). Участок Хизоваара известен своими высокобарическими метасоматитами (по работам С.А. Бушмина и В.А. Глебовицкого, за 1978-1983 г.), как месторождение кианитовых руд, мелкочешуйчатого мусковита (работы В.В. Щипцова с коллегами), а также красивыми коллекционными образцами.

При картировании Топозеро-Керетьской площади на южном берегу озера Верхнее Кереть был выделен своеобразный комплекс кристаллических сланцев, названный свитой Хизо-вара. Он включал сланцы (мусковито-гранатовые и двуслюдяно-гранатовые, с подчиненным распространением кианитовых и кианит-ставролитовых сланцев), гнейсы и амфиболиты. Первые описания Хизоваарского кианитового месторождения приводятся в работах профессора П.А. Борисова (1932 г.) и Н.А. Волотовской (за 1941, 1947 г.). Геолого-технологическое изучение кианитовых руд Хизоваарской свиты началось с 1946 года (Хизоваарское..., 1988) и продолжается в ИГ КарНЦ РАН под руководством В.В. Щипцова. Современные представления о геологическом строении участка Хизоваара, возрасте пород и рудной минерализации приведены в работах В.Н. Кожевникова (Кожевников, 2000; и ссылки в ней), С.И. Рыбакова и др. В данной статье более подробно рассматривается минеральная ассоциация фукситовых сланцев, генезис и типоморфные особенности хромсодержащих минералов. Опубликованная в литературе информация по метаморфическим минералам дополнена новыми данными, полученными с использованием электронного сканирующего микроскопа VEGA II LSH с микроанализатором INCA Energy-350. 


\section{Минеральное разнообразие участка Хизоваара}

Кианит (дистен) $\mathrm{Al}_{2}\left[\mathrm{SiO}_{4}\right] \mathrm{O}$ широко распространен в Беломорье и в Северо-Карельских архейских зеленокаменных структурах (ЗКС). Он входит в состав метаморфизованных высокоглиноземистых сланцев, амфиболитов и метасоматитов (проявления Тербеостров-Шуерецкое, Хизоваара, Хитостров, широко распространен восточнее озера Кереть, на участках Винга, Степанова Ламба, Еловое). В метасоматитах Хизоваары кианит входит в состав 3-7 минеральных парагенезисов, так называемых хизоваритов, и характеризует области повышенных давлений 5-8 кб (по В.А. Глебовицкому и С.А. Бушмину). Высокое содержание в составе кианита $\mathrm{Al}_{2} \mathrm{O}_{3}-63.1 \%$ позволяет использовать минерал как глиноземистое сырье для производства высокоогнеупорного материала - муллита, алюмокремниевых сплавов силуминов (Щипцов, 2005; и ссылки в ней). В С. Карелии известно 9 месторождений кианит-содержащих руд, внесенных в кадастр Р. Карелия, однако они пока не разрабатываются.
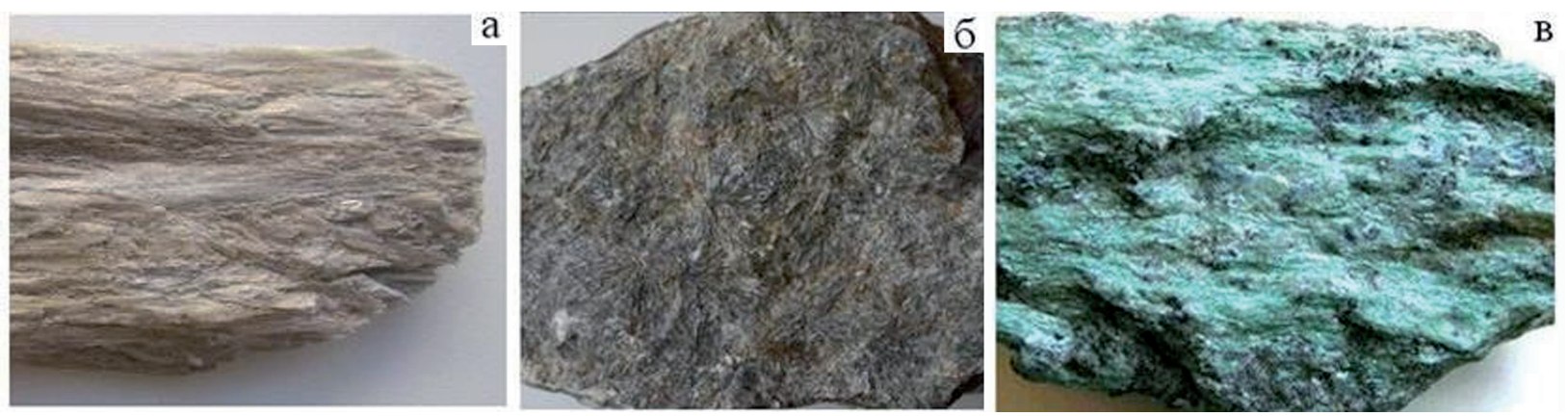

Рис. 1. Различные морфологические типы кианита месторождения Хизоваара.

a - серый игольчатый, б - серый радиально-лучистый; в - синий коротко-призматический из фукситовых сланцев.

Fig. 1. Various morphological types of kyanite from the Khizovaara deposit. $\mathrm{a}$ - grey spicular; $\mathrm{b}$ - grey radiate-fibrous; $\mathrm{c}$ - blue short-prismatic of fucsite schists.

Таблица 1. Состав кианитов Хизоваары и других участков С. Карелии (мас. \%). Table 1. Composition of kyanites from Khizovaara and other prospects in North Karelia, wt. \%.

\begin{tabular}{|c|c|c|c|c|c|c|c|c|c|c|c|c|c|}
\hline $\begin{array}{c}\text { Компо- } \\
\text { ненты }\end{array}$ & 1 & 2 & 3 & 4 & 5 & 6 & 7 & 8 & 9 & 10 & 11 & 12 & 13 \\
\hline $\mathrm{Al}_{2} \mathrm{O}_{3}$ & 61.56 & 61.93 & 60.45 & 63.46 & 59.86 & 60.43 & 59.67 & 57.48 & 61.51 & 59.65 & 59.94 & 60.53 & 60.48 \\
\hline $\mathrm{SiO}_{2}$ & 38.44 & 38.07 & 39.55 & 36.54 & 39.25 & 38.49 & 38.75 & 39.69 & 36.83 & 38.75 & 38.78 & 39.47 & 38.78 \\
\hline $\mathrm{Cr}_{2} \mathrm{O}_{3}$ & & & & & 0.89 & 1.08 & 1.58 & 2.84 & 1.66 & 1.60 & 1.28 & & \\
\hline $\mathrm{FeO}$ & & & & & & & & & & & & & 0.74 \\
\hline Сумма & 100 & 100 & 100 & 100 & 100 & 100 & 100 & 100 & 100 & 100 & 100 & 100 & 100 \\
\hline № обр. & 2591 & 2593 & 2593 & Щ & Х-14 & Х-17 & Х-27 & Х-31 & Х-25 & Х-27 & Х-27 & СЛ & 4962 \\
\hline
\end{tabular}

Примечание. 1 - серый радиально-лучистый и 2-3 - серый игольчатый кианит; 4 - средний состав серого кианита из метасоматитов линзы Южной (по В.В. Щипцову с коллегами); 5-11 - синий кианит из фукситовых сланцев участка Хизоваара. Для сравнения: 12 - голубой кианит из метасоматитов участка Степанова Ламба. 13 - голубой кианит из гранат-дистен-биотитовых сланцев участка Тербеостров.

Кианит Хизоваары образует удлиненные или коротко-уплощенные, волокнистые и радиальнолучистые кристаллы (рис. 1 а, б). Светло-серые кианиты наиболее распространены в Южной линзе Хизоваарского месторождения. Они образуют почти мономинеральные срастания, имеют стандартный состав, по работам В.В. Щипцова с соавторами (табл. 1/1-3). Кианитовые руды содержат кианит, кварц, мусковит, второстепенные (плагиоклаз, гранат, биотит, графит), рудные (пирит) и акцессорные минералы (рутил, ильменит). По своим ресурсам месторождение Хизоваара отнесено к 
группе объектов государственного резерва, запасы кианита подсчитаны для Южной линзы (Минерально..., 2006). Как коллекционный материал (и даже как ювелирный) минерал привлекает своим ярким голубым цветом. На других участках Хизоваары в гранат-кианит-биотитовых сланцах минерал имеет голубой цвет.

На участке Фукситовом в изумрудно-зеленых фукситовых сланцах в ассоциации с зеленым фукситом, кварцем и коричневым ставролитом встречается коротко-призматический кианит яркосинего цвета (рис. 1 в). Синие кианиты ассоциирующие с фукситом, в отличие от «серых», содержат примесь $\mathrm{Cr}_{2} \mathrm{O}_{3}$ 0.77-2.84 \% (табл. 1/4-7), при этом часть $\mathrm{Al}$ в минерале замещается Cr. Линза Фукситовая, благодаря присутствию ярко окрашенных минералов, рассматривается как месторождение поделочного камня.

Ставролит $(\mathrm{Fe}, \mathrm{Mg}) \mathrm{Al}_{4}\left[\mathrm{SiO}_{4}\right]_{2} \mathrm{O}_{2}(\mathrm{OH})_{2}$. Название минерала произошло от часто встречающихся крестообразных двойников (в переводе с греческого языка «ставрос»-крест). Однако в Карелии, в отличие от Кольского п-ова (Нерадовский, Войтеховский, 2012), крупные крестообразные кристаллы встречаются редко. В С. Карелии более распространен коротко-призматический ставролит (размером от 2 до 10 мм), иногда с двойниковыми срастаниями. Минерал имеет темно-коричневый цвет, твердость $\sim 7$. На участке Хизоваара, а также в других структурах С. Карелии (Винга, Степанова Ламба) ставролит встречается в сланцах (с альмандином, кианитом, кварцем, мусковитом), в ставролитовых кварцитах повышенной железистости, либо в ставролит-гранатовых метасоматитах. Ставролит обычно выделяется как порфиробластический и содержит включения других минералов. Он бывает «нашпигован» кварцем, кианитом и разнообразными акцессориями. В породах участка Хизоваара ставролит содержит незначительную примесь Mg, Zn (Бубнова и др., 2010) (табл. 2/1-2).

Таблица 2. Состав ставролитов участка Хизоваара (мас. \%).

Table 2. Mineral association of fuchsite schists (wt. \%).

\begin{tabular}{|c|c|c|c|c|c|c|c|c|c|c|c|}
\hline Компонент & 1 & 2 & 3 & 4 & 5 & 6 & 7 & 8 & 9 & 10 & 11 \\
\hline $\mathrm{MgO}$ & 1.92 & 2.18 & 1.57 & 1.60 & 1.89 & 1.93 & 1.68 & 1.67 & 2.13 & 2.31 & 2.11 \\
\hline $\mathrm{Al}_{2} \mathrm{O}_{3}$ & 53.64 & 53.53 & 51.26 & 50.53 & 50.62 & 50.44 & 51.14 & 50.80 & 52.43 & 52.59 & 53.54 \\
\hline $\mathrm{SiO}_{2}$ & 20.00 & 27.82 & 28.75 & 29.90 & 29.42 & 29.85 & 29.78 & 29.75 & 30.37 & 30.39 & 30.32 \\
\hline $\mathrm{TiO}_{2}$ & 0.88 & 0.79 & 1.12 & 0.79 & 0.67 & 0.73 & 0.90 & 0.81 & 0.75 & 0.79 & 0.83 \\
\hline $\mathrm{Cr}_{2} \mathrm{O}_{3}$ & & & 2.77 & 2.70 & 2.97 & 2.75 & 2.40 & 2.74 & & 0.58 & \\
\hline $\mathrm{FeO}$ & 13.20 & 12.44 & 13.10 & 12.95 & 13.03 & 12.61 & 12.72 & 12.62 & 14.32 & 13.33 & 13.21 \\
\hline $\mathrm{ZnO}$ & 1.12 & 1.29 & 1.43 & 1.53 & 1.41 & 1.70 & 1.39 & 1.62 & & & \\
\hline$\Sigma$ & 100 & 100 & 100 & 100 & 100 & 100 & 100 & 100 & 100 & 100 & 100 \\
\hline № обр. & $\mathrm{B}-181$ & $\mathrm{C} Г$ & $\mathrm{X}-2-1$ & $\mathrm{X}-2-2$ & $\mathrm{X}-3$ & $\mathrm{X}-9$ & $\mathrm{X}-22$ & $\mathrm{X}-12$ & $\mathrm{C}-2$ & $\mathrm{C}-4$ & С-5 \\
\hline
\end{tabular}

Примечание. 1-8 - участок Хизоваара. 1-2 - из работы (Бубнова и др., 2010): 1 - ставролит-гранат-биотитовый гнейс (Высота 181); 2 - ставролит-гранатовый метасоматит (Ставролитовая горка); 3-8 - ставролит из кианитфукситовых сланцев участка Фукситовый (Хизоваара). 9-11 - ставролит из кианит-мусковитовых сланцев участка Степанова Ламба (для сравнения). Анализы приведены к 100 \%.

На проявлении Фукситовом темно-коричневый мелкозернистый ставролит ассоциирует с фукситом, синим кианитом (рис. 1 в) и содержит многочисленные мелкие включения акцессорных оксидов и сульфидов (рис. 2 а-в). По своему химическому составу ставролит-кианит-фукситовые сланцы выделяются повышенными содержаниями $\mathrm{Cr}, \mathrm{Ni}, \mathrm{Co}$. В составе ставролита установлено $\mathrm{Cr}_{2} \mathrm{O}_{3}$ 2.4-2.97 \%, $\mathrm{ZnO} 1.39-1.70 \%, \mathrm{MgO} 1.57-1.93 \%$, $\mathrm{TiO}_{2}$ 0.67-1.12 \% (табл. 2). В кристаллической структуре минерала $\mathrm{Fe}^{2+}$ изоморфно замещается $\mathrm{Mg}$ и $\mathrm{Zn}, \mathrm{Al}-\mathrm{Cr}$ и Ті. Избыток этих элементов, устанавливаемых в составе ставролита, сопровождается выпадением и собственных минералов - акцессорных шпинелидов.

Гранат (альмандин) самый распространенный минерал метаморфических пород на участке Хизоваара. Гранатовые руды охарактеризованы в работах В.В. Щипцова с коллегами (Щипцов и др. 


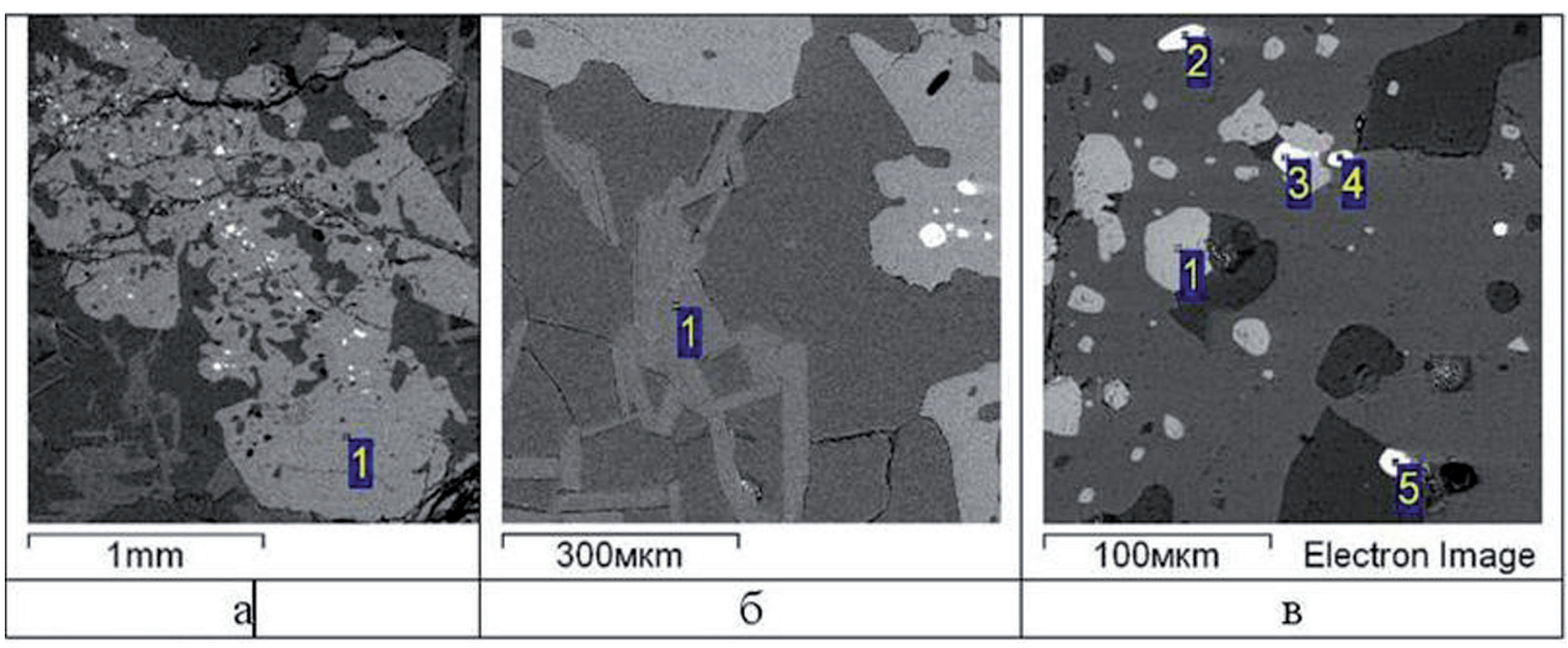

Рис. 2. Минеральная ассоциация фукситовых сланцев.

1 - кианит-фукситовый сланец со ставролитом (1) и рудными минералами, 2 - фуксит (1) и ставролит (светлосерый) с включениями рудных минералов (белые), 3 - алюмохромпикотит (1) и герсдорфит (2-5) в ставролите и кварце.

Fig. 2. Mineral association of fuchsite schists.

1 - kyanite-fuchsite schist with staurolite (1) and ore minerals, 2 - fuchsite (1) and staurolite (light grey) with inclusions of ore minerals (white), 3 - alumochrome picotite (1) and gersdorffite (2-5) in staurolite and quartz.

Таблица 3. Состав алюмохромовых шпинелидов из фукситовых сланцев (мас. \%).

Table 3. Composition of alumochromium spinellids from fuchsite schists (wt. \%).

\begin{tabular}{|c|c|c|c|c|c|c|c|c|c|c|}
\hline Компонент & 1 & 2 & 3 & 4 & 5 & 6 & 7 & 8 & 9 & 10 \\
\hline $\mathrm{Al}_{2} \mathrm{O}_{3}$ & 28.54 & 27.41 & 21.60 & 27.68 & 28.36 & 27.63 & 23.20 & 14.30 & 20.32 & 21.20 \\
\hline $\mathrm{Cr}_{2} \mathrm{O}_{3}$ & 31.34 & 33.19 & 33.25 & 32.00 & 31.78 & 32.35 & 39.53 & 49.64 & 42.25 & 42.79 \\
\hline $\mathrm{V}_{2} \mathrm{O}_{5}$ & 0.67 & 0.73 & 0.65 & 0.75 & 0.56 & 0.88 & & & & \\
\hline $\mathrm{FeO}$ & 33.48 & 33.07 & 33.36 & 33.86 & 34.03 & 33.43 & 34.06 & 33.10 & 33.42 & 32.91 \\
\hline $\mathrm{MgO}$ & 0.94 & 0.99 & 1.02 & 1.06 & 0.56 & 1.12 & & & 0.78 & \\
\hline $\mathrm{ZnO}$ & 5.03 & 4.60 & 4.11 & 4.47 & 4.47 & 4.60 & 3.22 & 2.96 & 3.24 & 3.10 \\
\hline$\sum$ & 100 & 100 & 100 & 100 & 100 & 100 & 100 & 100 & 100 & 100 \\
\hline
\end{tabular}

Примечание. 1-7 - алюмохромпикотит цинк-содержащий; 8-10 - алюмохромит цинк-содержащий.

Таблица 4. Состав герсдорфита из фукситовых сланцев (мас. \%).

Table 4. Composition of gersdorffite from fuchsite schists (wt. \%).

\begin{tabular}{|c|c|c|c|c|c|c|c|c|c|c|c|}
\hline Элемент & 1 & 2 & 3 & 4 & 5 & 6 & 7 & 8 & 9 & 10 & 11 \\
\hline $\mathrm{S}$ & 18.19 & 18.41 & 17.95 & 18.14 & 16.88 & 18.65 & 20.03 & 17.98 & 18.37 & 18.92 & 17.39 \\
\hline $\mathrm{Fe}$ & 9.13 & 7.23 & 8.80 & 9.73 & 8.60 & 8.14 & 10.00 & 9.08 & 8.75 & 9.06 & 8.20 \\
\hline $\mathrm{Co}$ & 8.04 & 8.67 & 7.68 & 7.61 & 7.64 & 7.55 & 7.96 & 7.54 & 7.32 & 7.31 & 6.63 \\
\hline $\mathrm{Ni}$ & 18.18 & 19.07 & 18.62 & 20.16 & 19.77 & 16.89 & 15.88 & 17.72 & 18.28 & 19.09 & 19.40 \\
\hline $\mathrm{As}$ & 48.46 & 46.63 & 46.95 & 44.35 & 47.10 & 48.77 & 46.12 & 47.69 & 47.29 & 45.62 & 48.47 \\
\hline $\mathrm{S}$ & 100 & 100 & 100 & 100 & 100 & 100 & 100 & 100 & 100 & 100 & 99.99 \\
\hline
\end{tabular}

2004; и др.). Гранат Высоты 181 - альмандин ( $\mathrm{MgO} 8.68-8.05, \mathrm{FeO} 26.72-33.36, \mathrm{MnO}_{2}$ 0.69-0.33, $\mathrm{CaO} 1.44-1.59$ \%). В фукситовых сланцах гранат встречается редко. 
Акиессорные и рудные минераль. Весьма необычны акцессорные минералы фукситовых сланцев. Среди них установлены хромовые шпинели, Co-Ni сульфоарсениды, рутил, ильменит. Редко встречаются апатит, монацит, бадделеит, циркон. Среди Cr-Fe-оксидов (рис. 2 в) наиболее распространенными являются шпинелиды ряда алюмохромит-алюмохромпикотит. Они содержат примеси $\mathrm{Mg}, \mathrm{Zn}, \mathrm{V}$ (табл. 3). Реже встречаются срастания рутила и ильменита. Рутил, в отличие от рутила кианитовых сланцев, содержит примесь $\mathrm{Cr}_{2} \mathrm{O}_{3}$ до 1.14 \%. Ильменит незначительно обогащен $\mathrm{MnO}$ $(0.60-0.91 \%)$.

В фукситовых сланцах в ставролите и кварце в срастании с хромшпинелидом обнаружен герсдорфит, образующий мелкие (1-10 мкм) кристаллы (рис. 2в). Герсдорфит содержит $\mathrm{Co}$ (до 6.63-8.67 \%) и $\mathrm{Fe}$ (7.23-10.00 \%), которые изоморфно замещают Ni (табл. 4). Их образование связано с тем, что процессы кислотного выщелачивания затронули расположенные вблизи коматииты, обеспечившие повышенные концентрации $\mathrm{Cr}, \mathrm{Ni}, \mathrm{Co}$.

Среди сульфидов в кианитовых породах участка Хизоваара наиболее распространен пирит. В южной части участка, севернее небольшого озера, вблизи проявления Фукситовый, в колчеданных рудах установлены пирит, пирротин, галенит, сфалерит. Повышенные концентрации $\mathrm{Au}$ (до 0.6 г/т) сопровождаются Bi до 220 г/т, Ag до 20 г/т, Pb 0.24 \%, Zn 1.6 \%, Cr 0.16 \% (Кожевников, 2000). Кианит-кварц-гранатовые метасоматиты с арсенопиритовой вкрапленностью содержат невысокие концентрации $\mathrm{Au}$ 0.046-0.078 и Pd 0.013-0.097 г/т. В гранат-содержащих метасоматитах с пиритом и арсенопиритом содержание $\mathrm{Au}-0,1-0.14$ г/т, $\mathrm{Pt}-0.015$ г/т; в прослоях с магнетитом - 0.01 г/т (материалы В.Н. Кожевникова, С.И. Рыбакова, В.Д. Слюсарева, автора).

В фукситовых сланцах встречаются редкие акцессории - бадделеит и циркон. В составе циркона установлено своеобразное гетерогенное замещение $\mathrm{Si}$ на $\mathrm{Al}, \mathrm{Fe}$ и $\mathrm{Cr}$. Циркон содержит $\mathrm{ZrO}_{2} 51.86$ \%, $\mathrm{SiO}_{2} 30.20 \%, \mathrm{Al}_{2} \mathrm{O}_{3} 14.06$ \%, примеси $\mathrm{FeO}$ до $3.16 \%$ и $\mathrm{Cr}_{2} \mathrm{O}_{3} 0.72 \%$. Результаты датирования цирконов ранних генераций фукситовых метасоматитов (по данным работ С.А. Сергеева и С.Б. Лобач-Жученко за 1993 г.) показали, что время их формирования ( 2.6 млрд. лет) близко времени внедрения поздних дацитовых даек участка Хизоваара. Именно с этим этапом магматизма, как предполагается, связаны ранние гидротермально-метасоматические преобразования пород (в том числе, коматиитов) участка Хизоваара. Метаморфические процессы преобразования циркона происходили 1.9 млрд. лет назад.

Слюды в разнообразных по составу сланцах Хизоваары представлены биотитом, мусковитом, фукситом. Свойства и возможности получения мелкочешуйчатого мусковита при обогащении кианитовых руд изучались Л.А. Данилевской и Л.С. Скамницкой (2012 г.).

Фукситовые сланцы обладают эффектными декоративными свойствами - изумрудно-зеленым цветом с вкраплениями синих кианитов (рис. 1 в). Фукситовые сланцы (метасоматиты) и фукситсодержащие кварциты - наиболее популярный коллекционный материал С. Карелии. Выходы на поверхность этих ярко-зеленых пород в Лоухском районе были известны геологам давно, но как поделочное сырье стали использоваться только в начале нынешнего века благодаря своей привлекательной окраске (материалы отчетов по камнесамоцветному сырью). Одной из первых публикаций по хромсодержащим минералам Хизоваары была работа (Волотовская, Жиров, 1948). В этой статье впервые приводятся анализы слюды, содержащей $\mathrm{Cr}_{2} \mathrm{O}_{3}$ (до 0.76-1.20 \%). Фуксит ассоциирует с кианитом, ставролитом, кварцем, реже встречаются гранат и Ca-Na-плагиоклаз. По результатам микрозондового изучения в составе фуксита установлены: $\mathrm{SiO}_{2} 41.03-51.26, \mathrm{Al}_{2} \mathrm{O}_{3} 30.56-36.24$, $\mathrm{K}_{2} \mathrm{O}$ 7.67-9.49, $\mathrm{Na}_{2} \mathrm{O}$ 1.39-2.10, $\mathrm{MgO}$ 0.39-0.82, $\mathrm{TiO}_{2}$ 0.53-0.92, $\mathrm{Cr}_{2} \mathrm{O}_{3}$ 0.99-1.40\%, FeO 0.71-1.46 (без воды). Цвет слюды обеспечивается вхождением в структуру минерала $\mathrm{Cr}$.

\section{Заключение}

В фукситовых сланцах впервые подробно разобрана рудная ассоциация. Обнаружены алюмохромиты и Со-герсдорфиты и установлен Cr-состав многих минералов. Типоморфные минералогогеохимические особенности фукситовых сланцев совместно с составом примесей практически 
во всех минералах подчеркивают, что эти породы сформировались в результате гидротермальнометасоматического изменения коматиитов (или их туфов) и последующего метаморфизма. Установлен повышенный фон благородных металлов. Коматииты образуют линзующиеся «пласты» и широко распространены в разных частях разреза Хизоваарской структуры (Кожевников, 2000). Фукситовые сланцы (метасоматически преобразованные породы) развиты в южной части структуры и прослеживаются по простиранию коматиитовых тел.

Работа выполняется по теме НИР № ГР АААА-А18-118020290084-7 ИГ КарНЦ РАН.

\section{Литература}

Волотовская Н.А., Жиров К.К. Хромсодержащие минералы свиты Хизовара // Известия КФНИ Базы АН СССР. 1948, № 1, С. 41-53.

Бубнова Т.П., Гаранжа А.В., Скамницкая Л.С. Типоморфные особенности ставролитов пялкъярвинской свиты (Приладожье) и Хизоваарской структуры (сев. Карелия) // Материалы VII Bсеpoc. с межд. участием Ферсман. научной сессии. Апатиты. 2010. С. 19-22.

Кожевников В.Н. Архейские зеленокаменные пояса Карельского кратона как аккреционные орогены. Петрозаводск. 2000. 222 с.

Минерально-сырьевая база Р. Карелия. 2006. Книга 2. 356 с.

Нерадовский Ю.Н., Войтеховский Ю.Л. Зональность ставролита из кристаллических сланцев Больших Кейв, Кольский полуостров // Труды КарНЦ РАН. 2012. № 3. С. 110-121.

Хизоварское кианитовое поле (Северная Карелия) / Щипцов В.В., Скамницкая Л.С. и др. Петрозаводск. 1988. 105 с.

Щипцов В.В. Кианит - эффективное сырье для производства огнеупоров: сферы потребления, производители и мировая торговля // Новые огнеупоры. № 8. 2005. С. 78-82.

Щипцов В.В., Бубнова Т.П. и др. Гранатовые руды Карелии // Петрозаводск: изд-во КарНЦ PAH. 2004. $208 \mathrm{c}$. 